\title{
The influence of hafnium impurities on the electrochemical performance of tantalum substituted $\mathrm{Li}_{7} \mathrm{La}_{3} \mathrm{Zr}_{2} \mathrm{O}_{12}$ solid electrolytes
}

\author{
Markus Mann ${ }^{1} \cdot$ Michael Küpers $^{1} \cdot$ Grit Häuschen $^{1} \cdot$ Martin Finsterbusch $^{1,2} \cdot$ Dina Fattakhova-Rohlfing $^{1,2}$. \\ Olivier Guillon ${ }^{1,2,3}$
}

Received: 27 April 2021 / Revised: 2 September 2021 / Accepted: 27 September 2021 / Published online: 7 October 2021

(c) The Author(s) 2021

\begin{abstract}
Garnet-based $\mathrm{Li}_{7} \mathrm{La}_{3} \mathrm{Zr}_{2} \mathrm{O}_{12}$ (LLZO) is considered one of the most promising oxide-ceramic solid electrolyte materials for inorganic all-solid-state batteries. Dopants and substituents like $\mathrm{Al}, \mathrm{Ta}, \mathrm{Nb}, \mathrm{Ga}$, and $\mathrm{W}$ were shown to have a high impact on the total ionic conductivity, increasing it from $10^{-6} \mathrm{~S} / \mathrm{cm}$ up to $10^{-3} \mathrm{~S} / \mathrm{cm}$. However, natural zirconium sources always contain a small amount of hafnium which could also act as dopant, but the separation of these two elements is complicated and expensive. In this work, we investigate the influence of various Hf-impurity concentrations on the performance of tantalum-doped LLZO. We synthesised $\mathrm{Li}_{6.45} \mathrm{Al}_{0.05} \mathrm{La}_{3} \mathrm{Zr}_{1.6-x} \mathrm{Hf}_{x} \mathrm{Ta}_{0.4} \mathrm{O}_{12}$ (LLZHO with $x=0$ - 1.6) via conventional solid-state synthesis and have demonstrated that up to $x=0.1$, hafnium impurities do not have a significant impact on the performance of the material. Above this concentration, the Li-ion conductivity is steadily reduced to around $70 \%$ when zirconium is fully substituted by hafnium resulting in $\mathrm{Li}_{6.45} \mathrm{Al}_{0.05} \mathrm{La}_{3} \mathrm{Hf}_{1.6} \mathrm{Ta}_{0.4} \mathrm{O}_{12}$. As the purity of $\mathrm{Zr}$ precursors has a great impact on their price, these findings can help to reduce the price of LLZO in general, as lower grade zirconium can be used in industrial scale applications.
\end{abstract}

Keywords LLZO $\cdot$ Garnet type $\cdot$ Solid electrolyte $\cdot$ Zirconium $\cdot$ Hafnium

\section{Introduction}

In the upcoming years, the demand for safe electrical energy storage devices with high energy density will increase drastically, due to the electrification of the transportation sector and stationary storage for renewable energies. Advanced electrochemical energy storage technologies like all-solidstate batteries (ASBs) are commonly regarded as next generation concepts and thus pushed towards commercialisation. They offer several advantages over conventional lithium ion batteries (LIBs), especially with regard to stability, safety,

Martin Finsterbusch

m.finsterbusch@fz-juelich.de

1 Institute of Energy and Climate Research - Materials Synthesis and Processing (IEK-1), Forschungszentrum Jülich GmbH, Wilhelm-Johnen-Strasse, 52425 Jülich, Germany

2 Helmholtz Institute Münster: Ionics in Energy Storage (IEK-12), Forschungszentrum Jülich $\mathrm{GmbH}$, Corrensstr. 46, 48149 Münster, Germany

3 Jülich Aachen Research Alliance, JARA-Energy, 52425 Jülich, Germany and energy density [1-3]. Lithium-stuffed garnet-based $\mathrm{Li}_{7} \mathrm{La}_{3} \mathrm{Zr}_{2} \mathrm{O}_{12}$ (LLZO) materials are particularly attractive solid electrolytes for all-solid-state batteries [4-8]. In 2007 Murugan et al. discovered the high ionic conductivity $\left(>10^{-4} \mathrm{~S} / \mathrm{cm}\right)$ in the compound $\mathrm{Li}_{7} \mathrm{La}_{3} \mathrm{Zr}_{2} \mathrm{O}_{12}$ and could show their potential as solid electrolyte for all-solid-state batteries [9]. Later, LLZO was found to be stable towards metallic lithium [10], allowing the use of Li-metal anodes, resulting into very high energy densities $[2,6,11]$. To stabilise the highest conducting cubic garnet phase, a doping of the material is necessary. In recent years, several dopants have been investigated to enhance the electrochemical performance of $\mathrm{Li}_{7} \mathrm{La}_{3} \mathrm{Zr}_{2} \mathrm{O}_{12}$, with the most promising candidates being $\mathrm{Al}, \mathrm{Ta}, \mathrm{Ga}, \mathrm{W}$, and $\mathrm{Nb}$ [7, 12-15]. Especially tantalum shows outstanding performances in terms of conductivity (up to $1.2 \cdot 10^{-3} \mathrm{~S} / \mathrm{cm}$ at room temperature [12]) and stability towards cathode materials [16-18] and also metallic lithium [19]. In our group, first fully inorganic ASBs were realised without the use of sintering additives or interface modifications, which rely on high total Li conductivity of LLZO to obtain high electrochemical performance [20,21]. Thus, a detailed understanding of the impact of the various 
dopants and impurities on the Li-ion conductivity and dendrite formation is essential to obtain reliable and reproducible cell performance.

The fact that element doping, even in trace amounts, has a high impact on the resulting properties of LLZO structures was also demonstrated, e.g. for tantalum and niobium. The chemical properties of both elements are very similar [22], and they are often found together in ores. However, their separation is complicated and expensive. Despite their chemical similarity, the substitution of tantalum by niobium decreases the ionic conductivity [23]. Furthermore, it reduces the stability of LLZO towards metallic lithium [19]. This example shows that even small changes in the LLZO structure can affect the Li-ion pathway and have a big influence on the performance of the material.

Another contamination that is always present are Hf impurities in $\mathrm{Zr}$ precursors, since natural zirconium ores always contain around 1-3\% of hafnium [24]. Hafnium and zirconium are chemically very similar, which makes the separation of this two materials even more expensive and complicated [25]. For example, in September 2020, the price for standard $\mathrm{ZrO}_{2}$ (containing up to $2 \%$ hafnium) was around $150 €$ per $\mathrm{kg}$, while for the purer one $(<100 \mathrm{ppm}$ hafnium), the price reached $500 €$ per $\mathrm{kg}$ [26]. Due to the chemical similarity of the two elements, the Hf impurities in zirconium play hardly any role for most applications. Therefore, also in case of LLZO, most authors do not consider or even mention whether they use standard up to $2 \%$ hafnium contaminated Zr- or Hf-free Zr precursor. In 2012, Tietz et al. investigated the influence of different $\mathrm{ZrO}_{2}$ precursors on the phase purity of Al-substituted LLZO. They found out that the starting materials with up to $2 \%$ hafnium show a higher phase purity of the final sintered LLZO than almost Hf-free $\mathrm{ZrO}_{2}$, but no electrochemical performance tests were performed at that time [27]. To close this knowledge gap, which is essential for industrial up-scaling of LLZO, we investigate the effect of various $\mathrm{Hf}$ contents on the conductivity and critical current density of sintered LLZO pellets.

The highest Li-ion conductivities for garnet-based materials were reached with a concentration of $6.4-6.5 \mathrm{Li}$ per unit cell $[13,29]$, and it is known that $\mathrm{Al}$ contaminations in Ta-doped LLZO act as sintering aids, allowing a higher density after sintering [30]. Therefore, we chose a tantalum and Al-substituted sample with the composition $\mathrm{Li}_{6.45} \mathrm{Al}_{0.05} \mathrm{La}_{3} \mathrm{Zr}_{1.6-x} \mathrm{Hf}_{x} \mathrm{Ta}_{0.4} \mathrm{O}_{12}$ (LLZHO) to investigate the influence of hafnium doping and compared the results to "natural" occurring Hf-impurities stemming from cheaper $\mathrm{ZrO}_{2}$ precursors.

To make the results more precise in the doping region expected in industrial applications, we put the focus on the zirconium rich side to investigate whether slight variations of the standard $\mathrm{Hf}$ contaminations in $\mathrm{ZrO}_{2}$ have an influence on the performance of the material in commercial ASBs.

\section{Experimental}

The garnet LLZHO materials were synthesised via a classical solid-state reaction in three steps. The starting materials $\mathrm{LiOH} \cdot \mathrm{H}_{2} \mathrm{O}$ (Applichem, 99\%), $\mathrm{La}_{2} \mathrm{O}_{3}$ (Merck, 99.9\%, $10 \mathrm{~h}$ pre-dried at $900{ }^{\circ} \mathrm{C}$ ), $\mathrm{ZrO}_{2}$ (Alfa Aesar, 99.5\%, hafnium $<100 \mathrm{ppm}$ ), $\mathrm{Ta}_{2} \mathrm{O}_{5}$ (Treibacher, 99.99\%), $\mathrm{Al}_{2} \mathrm{O}_{3}$ (Inframat, $99.9 \%$ ), and $\mathrm{HfO}_{2}$ (Alfa Aesar, 99\%) were weighed in an analytical balance (Quintix 224-1S, Sartorius AG, Göttingen, Germany). An excess of $20 \% \mathrm{LiOH} \cdot \mathrm{H}_{2} \mathrm{O}$ was used to prevent a loss of lithium during sintering. All samples were prepared in $50 \mathrm{~g}$ batches and are listed in Table 1. One sample was produced using the cheaper Hf-contaminated $\mathrm{ZrO}_{2}$ (Alfa Aesar, 99.5\%, <2\% hafnium). This $\mathrm{ZrO}_{2}$ precursor contains an unknown $\mathrm{Hf}$ content below $2 \%$ according to the manufacturer. Since for most sellers this is the regular $\mathrm{ZrO}_{2}$, we are referring to this sample as our standard sample with the sample ID: Hf_St.
Table 1 Stoichiometries of the prepared samples with abbreviations

\begin{tabular}{llll}
\hline $\begin{array}{l}\text { Hf concentration on } \\
\text { the 16a site }\end{array}$ & Composition & $\begin{array}{l}\text { Mol-fraction of hafnium } \\
\text { per unit cell }\end{array}$ & Abbreviation \\
\hline $0 \%$ & $\mathrm{Li}_{6.45} \mathrm{Al}_{0.05} \mathrm{La}_{3} \mathrm{Zr}_{1.6} \mathrm{Ta}_{0.4} \mathrm{O}_{12}$ & 0 & $\mathrm{Hf0}$ \\
$1 \%$ & $\mathrm{Li}_{6.45} \mathrm{Al}_{0.05} \mathrm{La}_{3} \mathrm{Zr}_{1.584} \mathrm{Hf}_{0.016} \mathrm{Ta}_{0.4} \mathrm{O}_{12}$ & 0.016 & $\mathrm{Hf0016}$ \\
$2 \%$ & $\mathrm{Li}_{6.45} \mathrm{Al}_{0.05} \mathrm{La}_{3} \mathrm{Zr}_{1.568} \mathrm{Hf}_{0.032} \mathrm{Ta}_{0.4} \mathrm{O}_{12}$ & 0.032 & $\mathrm{Hf0032}$ \\
$3 \%$ & $\mathrm{Li}_{6.45} \mathrm{Al}_{0.05} \mathrm{La}_{3} \mathrm{Zr}_{1.552} \mathrm{Hf}_{0.048} \mathrm{Ta}_{0.4} \mathrm{O}_{12}$ & 0.048 & $\mathrm{Hf0048}$ \\
$4 \%$ & $\mathrm{Li}_{6.45} \mathrm{Al}_{0.05} \mathrm{La}_{3} \mathrm{Zr}_{1.536} \mathrm{Hf}_{0.064} \mathrm{Ta}_{0.4} \mathrm{O}_{12}$ & 0.064 & $\mathrm{Hf0064}$ \\
$5 \%$ & $\mathrm{Li}_{6.45} \mathrm{Al}_{0.05} \mathrm{La}_{3} \mathrm{Zr}_{1.52} \mathrm{Hf}_{0.08} \mathrm{Ta}_{0.4} \mathrm{O}_{12}$ & 0.08 & $\mathrm{Hf008}$ \\
$10 \%$ & $\mathrm{Li}_{6.45} \mathrm{Al}_{0.05} \mathrm{La}_{3} \mathrm{Zr}_{1.44} \mathrm{Hf}_{0.16} \mathrm{Ta}_{0.4} \mathrm{O}_{12}$ & 0.16 & $\mathrm{Hf016}$ \\
$25 \%$ & $\mathrm{Li}_{6.45} \mathrm{Al}_{0.05} \mathrm{La}_{3} \mathrm{Zr}_{1.2} \mathrm{Hf}_{0.4} \mathrm{Ta}_{0.4} \mathrm{O}_{12}$ & 0.4 & $\mathrm{Hf04}$ \\
$50 \%$ & $\mathrm{Li}_{6.45} \mathrm{Al}_{0.05} \mathrm{La}_{3} \mathrm{Zr}_{0.8} \mathrm{Hf}_{0.8} \mathrm{Ta}_{0.4} \mathrm{O}_{12}$ & 0.8 & $\mathrm{Hf08}$ \\
$100 \%$ & $\mathrm{Li}_{6.45} \mathrm{Al}_{0.05} \mathrm{La}_{3} \mathrm{Hf}_{1.6} \mathrm{Ta}_{0.4} \mathrm{O}_{12}$ & 1.6 & $\mathrm{Hf16}$ \\
$1-2 \%$ & $\mathrm{Li}_{6.45} \mathrm{Al}_{0.05} \mathrm{La}_{3} \mathrm{Zr}_{1.6} \mathrm{Ta}_{0.4} \mathrm{O}_{12}$ & $\mathrm{Hf} \mathrm{St}$ \\
\hline
\end{tabular}


The weighed powder was mixed and ground with using a mortar mill RM 200 (Retsch GmbH, Haan, Germany) with tungsten-carbide crucible and pestle for $1 \mathrm{~h}$ at a speed of $100 \mathrm{rpm}$. From the homogenised powder, pellets were pressed (uniaxial, 45-mm diameter, at $20 \mathrm{MPa}$ ) and calcined twice for $20 \mathrm{~h}$ in alumina crucibles. The first calcination step was performed at $850{ }^{\circ} \mathrm{C}$, while the second one was performed at $1000{ }^{\circ} \mathrm{C}$. After each calcination step, the pellets were ground to powder and repressed to pellets. The final pellets for the sintering step were prepared from roughly $7 \mathrm{~g}$ powder and were uniaxial pressed into a 13-mm-diameter press mould with a strength of $120 \mathrm{MPa}$. These pellets were placed on a magnesium oxide plate. To avoid possible contamination of the $\mathrm{MgO}$, a layer of the same powder was applied between the $\mathrm{MgO}$ plate and the pellets. The pellets were placed in a closed alumina crucible and sintered in air at $1175^{\circ} \mathrm{C}$ for $10 \mathrm{~h}$ in a high temperature muffle furnace (RHF 15 with a Eurotherm 3508 temperature controller, Carbolite Gero GmbH \& Co. KG, Neuhausen, Germany). The heating ramp for the calcination and sintering steps was steadily controlled at $5 \mathrm{~K} \cdot \mathrm{min}^{-1}$ with a natural cooling rate of $5 \mathrm{~K} \cdot \mathrm{min}^{-1}$ or lower.

To obtain information about the phase purity and structure of the samples, characterisations were performed using X-ray diffraction (XRD). The instrument is a Bruker D4 Endeavour instrument using $\mathrm{Cu}-\mathrm{K} \alpha$ radiation and equipped with a 1D detector LYNXEY and a DIFFRAC plus BASIC package, which was released in 2009. All samples were measured from 10 to $140^{\circ} 2 \Theta$ with $0.02^{\circ}$ step sizes. For the measurements, the pellets were crushed and mortared to fine powder to ensure good statistics. Rietveld refinements were performed for all samples using the program Fullprof [31]. A structural starting model was used with the space group $I a \overline{3} d$ and atomic coordinates; thermal and occupation parameters were taken from neutron diffraction experiments [32]. The impurities could not be stably co-refined due to their small amounts $(<5 \%)$. The background was fitted using a 6-polynomial function, and the profiles were assumed as asymmetric pseudo-Voigt functions. The lattice parameters were refined, while the atomic positions and thermal parameters were kept according to the neutron diffraction experiments. The ratio between tantalum, zirconium and hafnium was kept at the ideal ratio from the weighted in elements, which corresponds well to the later shown ICP-OES results.

Inductively coupled plasma optical emission spectrometry (ICP-OES; Thermo Elemental, IRIS Intrepid iCAP 7600 , Waltham, USA) was used to measure the stoichiometry of the sintered LLZO:Al:Ta:Hf samples by dissolving two 50-mg sample weights in $4 \mathrm{~mL}$ sulfuric acid with the addition of $2 \mathrm{~g}$ ammonium sulphate under strong heating.

The density was measured geometrically. The pellet geometries can be found in Table 2. The rel. density was calculated as the ratio between the geometrically determined density and the crystallographic density determined by the Rietveld refinements.

For microstructural investigations all samples were embedded in epoxy and mirror polished. Scanning electron measurements were taken on a Hitachi, TM 3000 tabletop microscope.

To measure the Li-ion conductivity, the prepared LLZO pellets were polished with $\mathrm{SiC}$ sandpaper up to 4000er grit to remove possible impurities from the surface. Gold blocking electrodes were applied via sputtering (Cressington 108auto Coater, Dortmund, Germany) onto both sides of the polished pellets. The dimensions of the measured pellets can be found in Table 2. Using a BioLogic VMP300 Multipotentiostat (Bio-Logic Sciences Instruments Ltd, Claix, France), the room temperature impedance of the pellets was measured, and the resistance and conductivity calculated from the fitted curves. The measured frequency was varied from $7 \mathrm{MHz}$ to $1 \mathrm{~Hz}$ with an electrical field perturbation of $10 \mathrm{mVmm}^{-1}$.
Table 2 Total conductivities and capacities of all samples from impedance spectroscopy. The relative density is calculated from the measured densities and the crystallographic density determined by Rietveld refinements

\begin{tabular}{lllllllll}
\hline Sample & $\begin{array}{l}m \\
(\mathrm{~g})\end{array}$ & $\begin{array}{l}h \\
(\mathrm{~mm})\end{array}$ & $\begin{array}{l}d \\
(\mathrm{~mm})\end{array}$ & $\begin{array}{l}\text { Total conductivity } \\
\left(10^{-3} \mathrm{~S} / \mathrm{cm}\right)\end{array}$ & $\begin{array}{l}\text { Capacitance } \\
\left(10^{-11} \mathrm{~F}\right)\end{array}$ & $\begin{array}{l}\rho(\mathrm{XRD}) \\
\left(\mathrm{g} / \mathrm{cm}^{3}\right)\end{array}$ & $\begin{array}{l}\rho(\mathrm{geo}) \\
\left(\mathrm{g} / \mathrm{cm}^{3}\right)\end{array}$ & $\begin{array}{l}\text { Rel. } \rho \\
(\%)\end{array}$ \\
\hline Hf0 & 5.3853 & 10.63 & 11.37 & 0.651 & 4.96 & 5.333 & 4.990 & 93.56 \\
Hf0016 & 6.2181 & 12.42 & 11.32 & 0.674 & 4.60 & 5.344 & 4.975 & 93.09 \\
Hf0032 & 4.888 & 9.57 & 11.45 & 0.607 & 5.29 & 5.359 & 4.960 & 92.56 \\
Hf0048 & 7.4451 & 14.28 & 11.53 & 0.600 & 4.79 & 5.367 & 4.993 & 93.04 \\
Hf0064 & 6.6321 & 13.23 & 11.34 & 0.706 & 4.93 & 5.375 & 4.963 & 92.34 \\
Hf008 & 7.078 & 13.84 & 11.5 & 0.612 & 4.80 & 5.385 & 4.924 & 91.43 \\
Hf016 & 6.9291 & 13.61 & 11.62 & 0.653 & 4.44 & 5.427 & 4.801 & 88.46 \\
Hf04 & 5.6904 & 11.15 & 11.34 & 0.578 & 4.81 & 5.554 & 5.053 & 90.98 \\
Hf08 & 5.5138 & 10.40 & 11.40 & 0.564 & 4.86 & 5.787 & 5.194 & 89.76 \\
Hf16 & 7.5474 & 12.49 & 11.42 & 0.455 & 4.77 & 6.223 & 5.899 & 94.80 \\
Hf_St & 6.8233 & 13.30 & 11.73 & 0.654 & 4.74 & 5.350 & 4.747 & 88.73 \\
\hline
\end{tabular}


To investigate the impact on dendrite formation, symmetrical $\mathrm{Li} / \mathrm{LLZO} / \mathrm{Li}$ cells were prepared. The sintered LLZO pellets were cut in discs with a thickness of roughly $1 \mathrm{~mm}$ by an IsoMet low speed diamond saw (ITW Test \& Measurement GmbH, Esslingen am Neckar, Germany). Afterwards, they were prepolished in air with SiC-sandpaper with a 800 er grit, transferred into an argon oven, and heated to $750{ }^{\circ} \mathrm{C}$ under static vacuum for $2 \mathrm{~h}$ to remove residual $\mathrm{Li}_{2} \mathrm{CO}_{3}$ from the surface. After cool-down, the discs were transferred directly into a glovebox (GS Glovebox Systemtechnik GmbH, Malsch, Germany). The pellet geometries can be found in Table 3 .

Both sides of pellets were then polished by SiC sandpaper with up to a 4000er grit, and freshly calendared lithium (99.9\%, Alfa Aesar) was manually pressed on the separators. To improve the contact, the symmetrical cell was placed between two nickel current collectors and heated to $300{ }^{\circ} \mathrm{C}$ for $5 \mathrm{~min}$. After cooling down to room temperature, the symmetrical cells were transferred into Swagelok cells, sealed, and taken out of the glovebox for analysis.

To determine the critical current density (CCD) for Lidendrite formation, lithium stripping and plating experiments were performed using the same BioLogic VMP-300 Multipotentiostat as before and a VT 4002EMC climate chamber (Vötsch Industrietechnik $\mathrm{GmbH}$, Balingen, Germany). The cells were heated to $60{ }^{\circ} \mathrm{C}$, and galvanostatic cycling with $1 \mathrm{~h}$ per current direction was performed, starting at $75 \mu \mathrm{A} / \mathrm{cm}^{2}$ with an increment of $25 \mu \mathrm{A} / \mathrm{cm}^{2}$ per cycle until voltage drops were observable. These voltage drops are our criterion for dendrite growth, since they indicate a micro short circuit. The temperature of $60{ }^{\circ} \mathrm{C}$ was chosen to minimise the influence of conductivity and to look more closely on other parameters.

\section{Results}

The XRD patterns of $\mathrm{Li}_{6.45} \mathrm{Al}_{0.05} \mathrm{La}_{3} \mathrm{Zr}_{1.6-x} \mathrm{Hf}_{x} \mathrm{Ta}_{0.4}$ samples with different hafnium content are shown in Fig. 1. For all investigated hafnium concentrations, the patterns correspond to almost phase pure cubic LLZO structure. Minor reflections in some samples could be indexed by the phases $\mathrm{Li}_{2} \mathrm{CO}_{3}$ (ICSD: 100324) [33] and $\mathrm{La}_{2} \mathrm{Li}_{0.5} \mathrm{Al}_{0.5} \mathrm{O}_{4}$ (ICSD: 202439) [34].

The crystal radius of $\mathrm{Hf}^{4+}(0.85 \AA)$ is slightly smaller than that of $\mathrm{Zr}^{4+}(0.86 \AA)$ in an octahedral environment [35]. Therefore, a slight decrease of the lattice parameter is expected for the incorporation of hafnium. Figure 2 shows

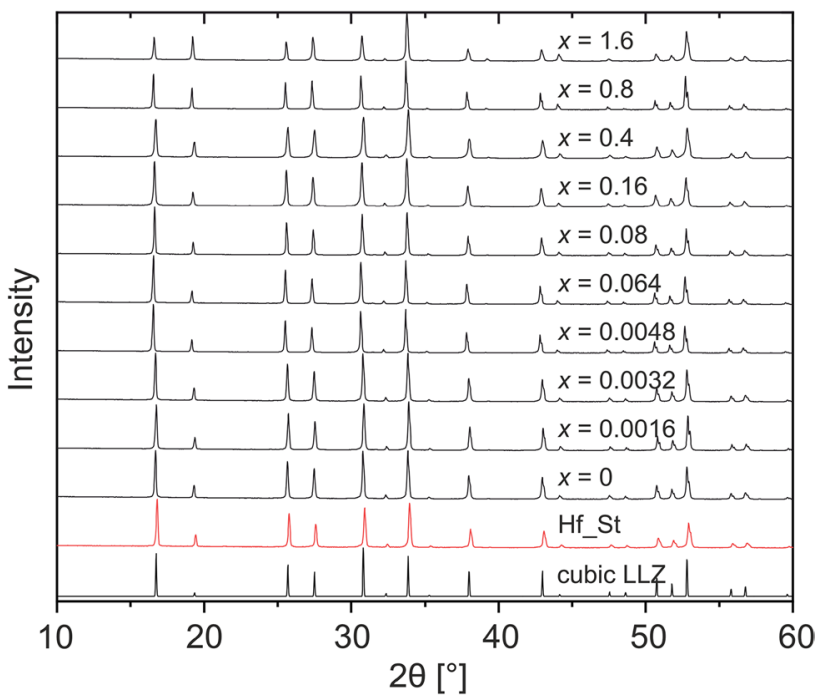

Fig. 1 The figure shows all XRD-pattern for $\mathrm{Li}_{6.45} \mathrm{Al}_{0.05} \mathrm{La}_{3} \mathrm{Zr}_{1.6-x} \mathrm{Hf}_{x} \mathrm{Ta}_{0.4}$ with $0 \leq \mathrm{x} \leq 1.6$ as well as in red the pattern for the Hf_St sample. At the bottom, the theoretical diffraction pattern of cubic LLZO is plotted [32]. It can be seen that the cubic garnet structure was formed in all samples
Table 3 Pellet geometry, geometrical density, resistance components, determined lithium conductivity, interface resistance between LLZO and lithium, and CCD of symmetrical Li-LLZO-Li cells

\begin{tabular}{lllllll}
\hline & Hf0_1 & Hf0_2 & Hf016 & Hf08 & Hf16 & Hf_St \\
\hline$m(\mathrm{~g})$ & 0.4942 & 0.4917 & 0.4510 & 0.4484 & 0.5375 & 0.4881 \\
$h(\mathrm{~mm})$ & 0.98 & 0.98 & 0.99 & 0.89 & 0.94 & 0.95 \\
$d(\mathrm{~mm})$ & 11.42 & 11.42 & 10.76 & 11.28 & 11.18 & 11.76 \\
$A\left(\mathrm{~cm}^{2}\right)$ & 1.024 & 1.024 & 0.9093 & 0.9993 & 0.9817 & 1.086 \\
$\rho(\mathrm{geo})\left(\mathrm{g} / \mathrm{cm}^{3}\right)$ & 4.923 & 4.898 & 5.010 & 5.042 & 5.825 & 4.730 \\
Rel. $\rho(\%)$ & 92.33 & 91.85 & 92.31 & 87.12 & 93.60 & 88.42 \\
$R_{\text {Bulk }}$ fraction $(\%)$ & 96.5 & 91.0 & 92.2 & 94.3 & 89.0 & 96.0 \\
$R_{\mathrm{GB}}$ fraction $(\%)$ & 3.5 & 9.0 & 7.8 & 5.7 & 11.0 & 4.0 \\
Cond. at RT $\left(10^{-3} \mathrm{~S} / \mathrm{cm}\right)$ & 0.73 & 0.76 & 0.571 & 0.50 & 0.46 & 0.63 \\
Interface resistance at RT b/w. & 16.22 & 7.24 & 22.29 & 9.35 & 1.48 & 28.47 \\
$\quad$ LLZO-Li $\left(\Omega \bullet \mathrm{cm}^{2}\right)$ & & & & & & \\
Critical current density $\left(\mu \mathrm{A} / \mathrm{cm}^{2}\right)$ & 550 & 350 & 425 & 325 & 300 & 450 \\
\hline
\end{tabular}




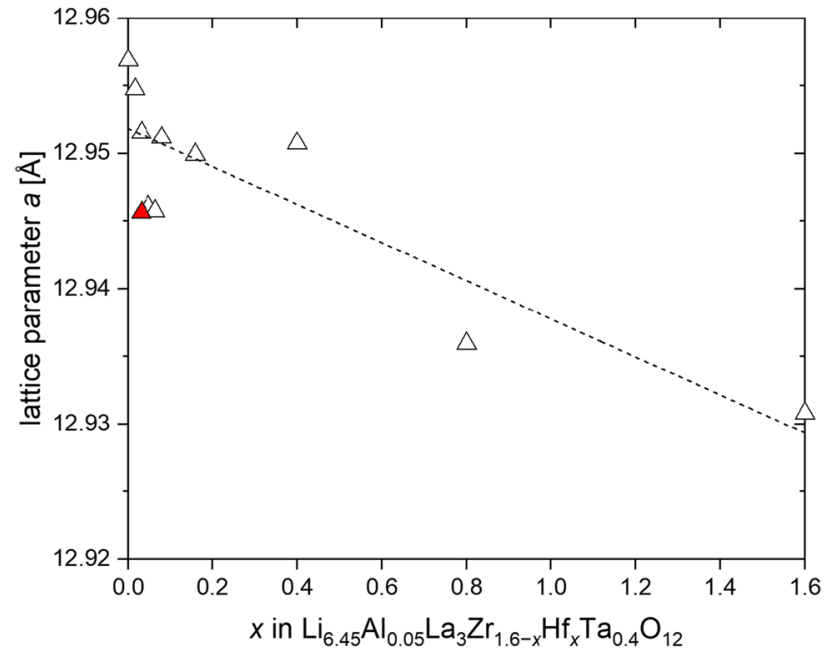

Fig. 2 Lattice parameters $a$ determined by Rietveld refinements of the diffraction pattern vs. $x$ in cubic $\mathrm{Li}_{6.45} \mathrm{Al}_{0.05} \mathrm{La}_{3} \mathrm{Zr}_{1.6-x} \mathrm{Hf}_{x} \mathrm{Ta}_{0.4} \mathrm{O}_{12}$. The red filled triangle is the Hf_St sample for comparison. The dashed line is a guide for the eye to visualise the decrease of the lattice parameter

the lattice parameter in relation to the $\mathrm{Hf}$ content. The lattice parameter shrinks from 12.951(1) $\AA$ for 0\% Hf to 12.931(1) $\AA$ for the fully substituted sample. This is just as expected for the smaller $\mathrm{Hf}$ ion.

To verify the elemental stoichiometry in the sintered samples, ICP-OES elemental analysis was performed. The resulting amounts of hafnium and zirconium are shown in Fig. 3 and correspond to the amounts which were weighted

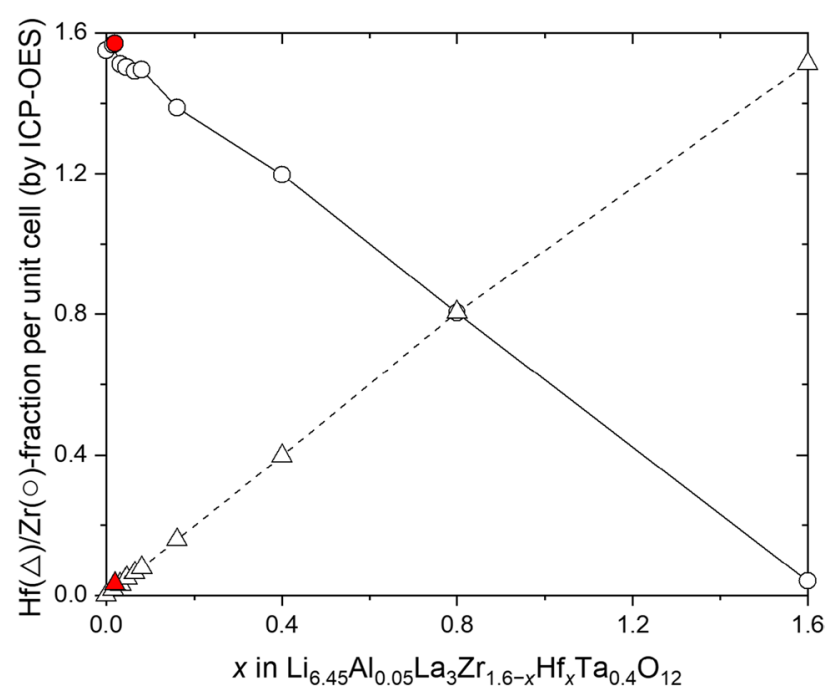

Fig. $3 \mathrm{Zr}$ and $\mathrm{Hf}$ content per unit cell determined by ICPOES are plotted against the weight in amount of Hf $(x$ in $\mathrm{Li}_{6.45} \mathrm{Al}_{0.05} \mathrm{La}_{3} \mathrm{Zr}_{1.6-x} \mathrm{Hf}_{x} \mathrm{Ta}_{0.4} \mathrm{O}_{12}$ ). Triangles are used for $\mathrm{Hf}$ and circles for Zr. The red filled symbols are the Hf_St sample for comparison in. The hafnium concentration in the Hf_St sample prepared using contaminated $\mathrm{ZrO}_{2}$ was $0.02 \mathrm{~mol} \%$, which corresponds to $1.3 \%$ of the total zirconium content. The hafnium content of this sample is therefore within the specified range $(<2 \%)$.

Figure 4 shows the density of different samples in relation to the hafnium content. As it can be seen from the obtained results, the low hafnium concentrations (up to 3\%) have practically no influence on the density of the samples, which is around $93 \%$. However, for higher levels of hafnium, there is a distinct effect on the density of the sintered pellets, continuously decreasing with the increasing amounts of hafnium to reach relative densities below $90 \%$ for $10 \%$ hafnium. The density remains relatively low $(\sim 90 \%)$ for the mixed samples and increases again for pure LLHO sample Hf16 to reach the highest measured density of $94.8 \%$. The reference sample Hf_St does not completely follow the trend, with a density of only $88.7 \%$ at an expected hafnium content of $1-2 \%$. Scanning electron micrographs of the samples Hf0, Hf0048, Hf08, and Hf16 are shown in Fig. 5. They reflect the measured relative densities, with a high density of Hf0 and Hf16, while a bigger porosity is observable for Hf0048 and Hf08.

The Nyquist plots of the impedance spectra of pellets with different hafnium concentrations show one slightly depressed semicircle in the high frequency region $(7 \mathrm{MHz}-30 \mathrm{kHz})$ and a capacitive tail in the low frequency region. The flattened semicircle corresponds to the bulk resistance and the grain boundaries of the LLZO and can be described with one R-CPE element. The fitted capacitances for all samples are in the region of $10^{-11} \mathrm{~F}$ and show that this semicircle is dominated by the bulk resistance. Unfortunately, a separation of the resistances into grain boundaries

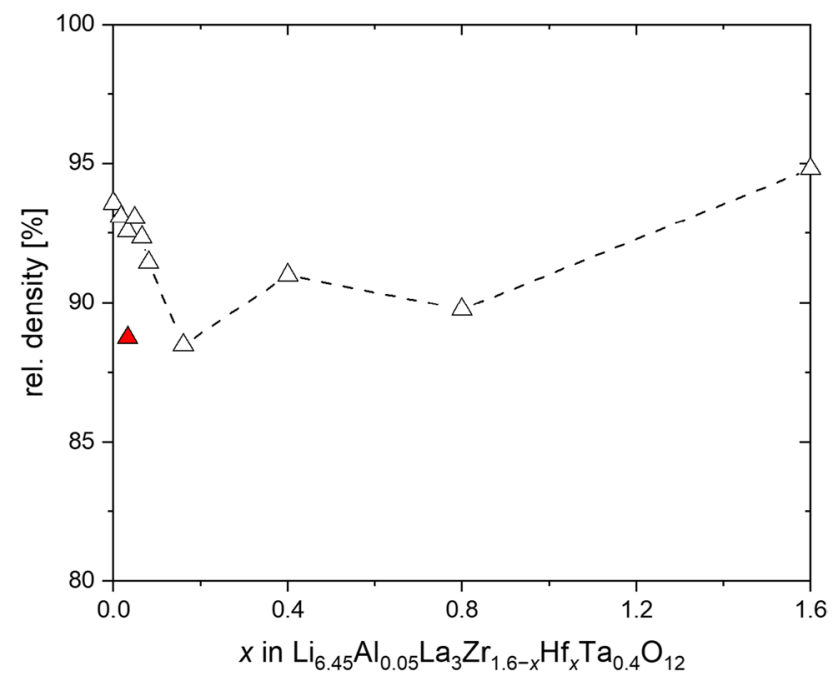

Fig. 4 Relative density of $\mathrm{Li}_{6.45} \mathrm{Al}_{0.05} \mathrm{La}_{3} \mathrm{Zr}_{1.6-x} \mathrm{Hf}_{x} \mathrm{Ta}_{0.4} \mathrm{O}_{12}$ in relation to the hafnium content $x$. The red filled triangle is the Hf_St sample for comparison 
Fig. 5 Scanning electron micrographs of the samples a HfO, b Hf0048, c Hf08, and d Hf16
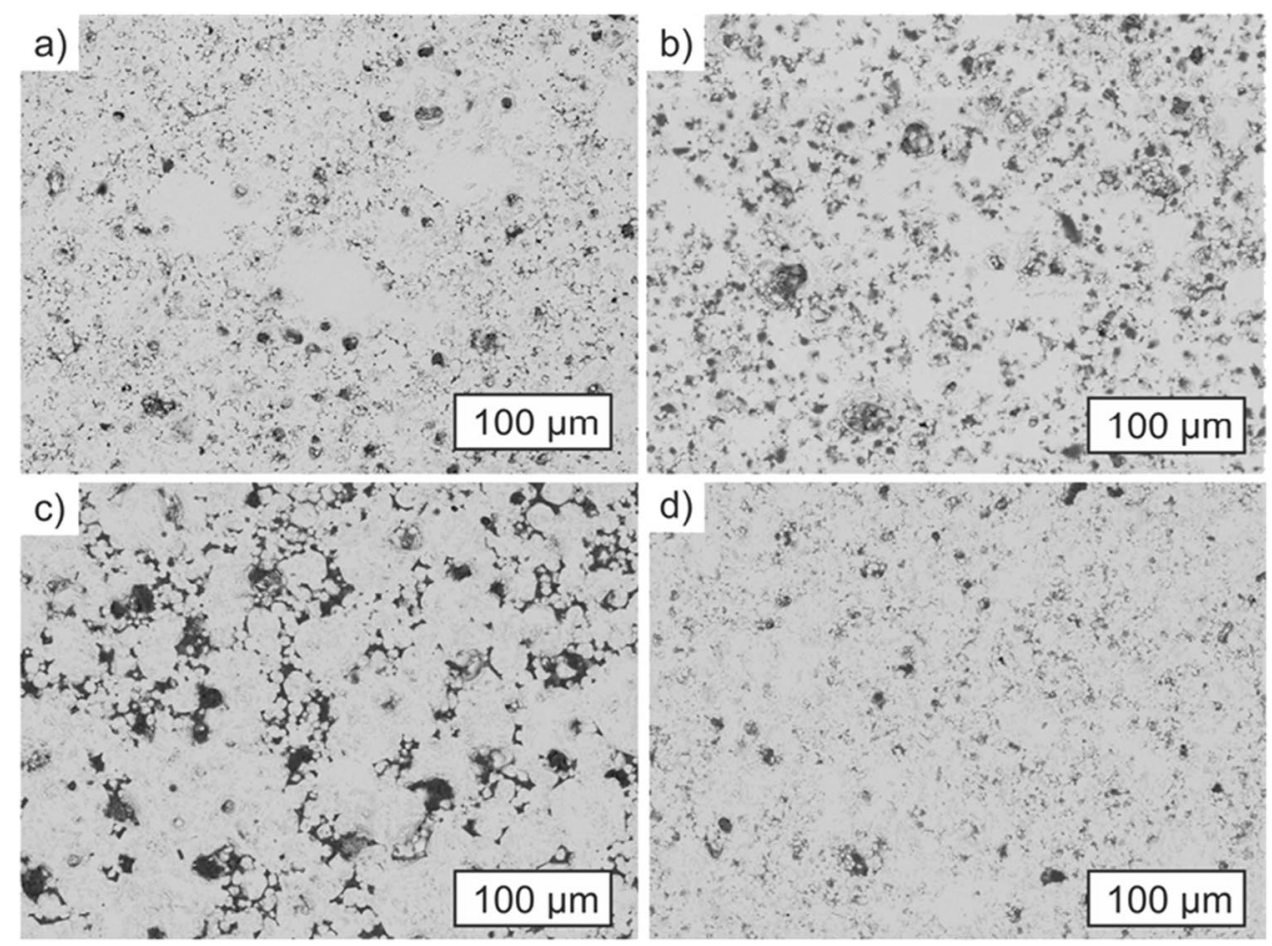

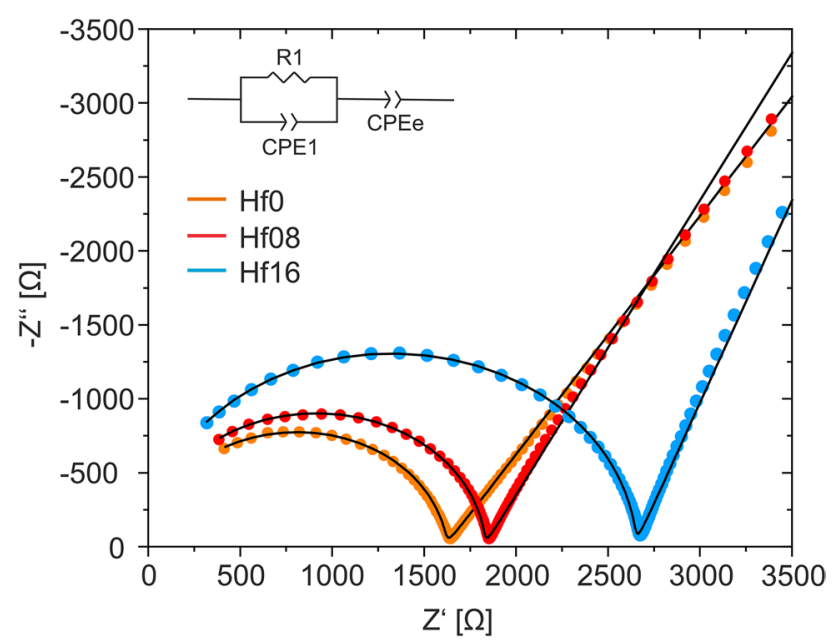

Fig. 6 Fitted and measured impedance spectra of Hf0, Hf08 and Hf16 samples

and bulk resistance was not possible with reasonable errors on the fitting parameters. The low frequency tail is a clear sign for ionic blocking electrodes, typical for gold electrodes, and has been reported before and may be described, e.g. by a CPE element $[4,9]$. The measured and fitted spectra for Hf0, Hf08, and Hf16 are shown in Fig. 6. The measured and fitted spectra for the other synthesised samples can be found in the supporting information in Figure S1. The total conductivities of the samples in relation to the hafnium content are shown in Fig. 7. The highest conductivities were

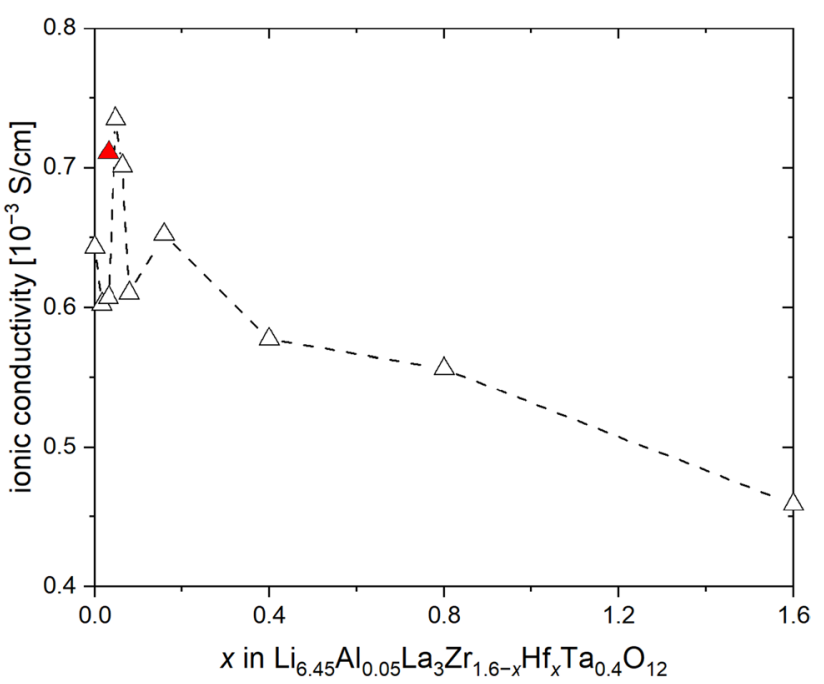

Fig. 7 Total ionic conductivities vs. $x$ in $\mathrm{Li}_{6.45} \mathrm{Al}_{0.05} \mathrm{La}_{3} \mathrm{Zr}_{1.6-x} \mathrm{Hf}_{x} \mathrm{Ta}_{0.4} \mathrm{O}_{12}$. The red filled triangle is the Hf_St powder sample

measured for hafnium contents below $10 \%\left(0.6-0.7 \cdot 10^{-3} \mathrm{~S} /\right.$ $\mathrm{cm})$. With increasing Hf content, the conductivity decreases and reaches a minimum of $0.45 \cdot 10^{-3} \mathrm{~S} / \mathrm{cm}$ for $\mathrm{Hf} 16$. The conductivity of Hf_St is with $0.64 \cdot 10^{-3} \mathrm{~S} / \mathrm{cm}$ in a good agreement with the other samples with similar hafnium contents, despite a lower relative density.

To investigate whether dendrite formation is affected by the hafnium content, impedance spectra of symmetric Li/ 
LLZO/Li cell were recorded first, and then critical current density (CCD) measurements were performed for five different compositions (Hf_St; Hf0; Hf016; Hf08; Hf16).

The measured impedance spectra show three contributing semicircles. Each spectrum was fit with three R-CPE elements. The first belongs to the bulk resistance of LLZO $\left(C_{\mathrm{Bulk}} \sim 10^{-11} \mathrm{~F}\right)$, the second one to the grain boundaries of LLZO $\left(C_{\mathrm{GB}} \sim 10^{-8} \mathrm{~F}\right)$, and the third one describes the interface resistance between LLZO and lithium. While the first two are used to calculate the total conductivity of the pellet and the fractions of bulk and grain boundaries resistance, the last resistance gives information about the contact between electrolyte and lithium. The measured and fit impedance spectrum of the symmetrical cell of Hf016 is shown in Fig. 8 and for the other samples in the supporting Information S2-S6. The fitted data can be found in Table 4 .

The CCD measurements show typical flat voltage plateaus for lower current densities. With increasing current densities, the voltage plateaus show an increasing slope which is a typical sign for a slow depletion of the active lithium at the $\mathrm{LLZO} / \mathrm{Li}$ interface and therefore rising interface resistance between LLZO and lithium [11]. The CCD measurement of Hf016 (Fig. 9) shows in the cycle at $425 \mu \mathrm{A} / \mathrm{cm}^{2}$ a voltage drop. This is a clear sign for a short circuit and

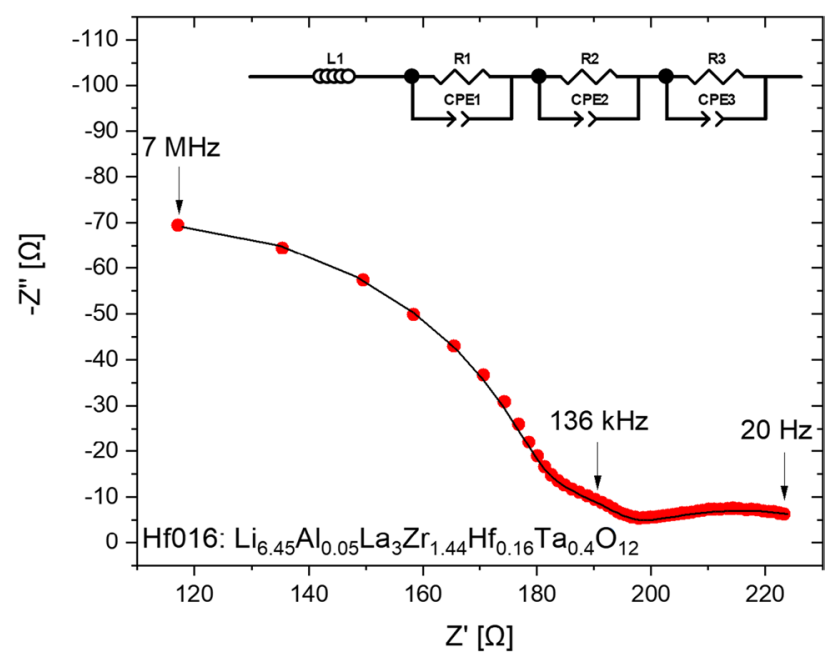

Fig. 8 Measured and fit impedance spectrum at $25{ }^{\circ} \mathrm{C}$ of the sample with $10 \%$ hafnium doping Hf016

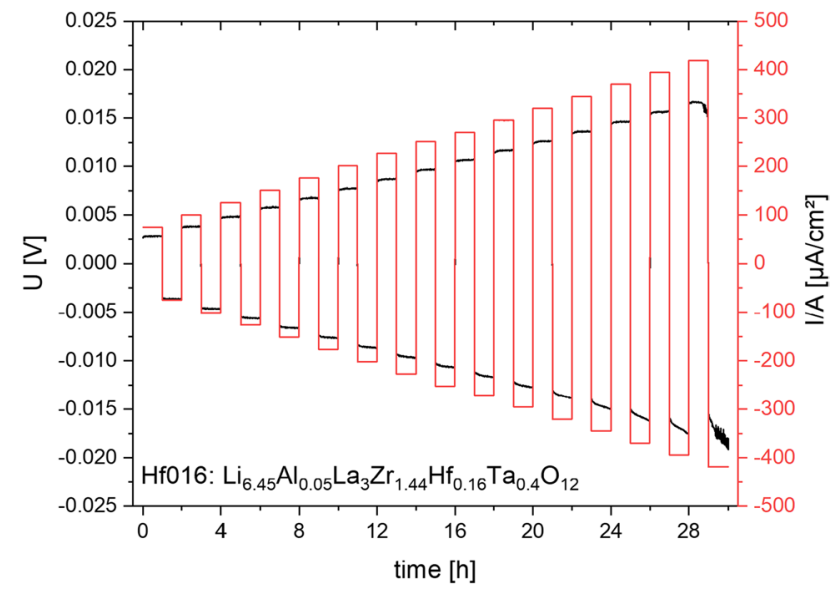

Fig. 9 Critical current density measurement at $60{ }^{\circ} \mathrm{C}$ for the sample with $10 \%$ hafnium doping Hf016

therefore dendrite formation. The determined CCD of all samples can be found in Table 3 .

\section{Discussion}

Table 5 summarises total conductivities of LLZO and LLHO with and without tantalum doping reported in the literature, as well as the results obtained in this work. For LLZO and LLHO, the tetragonal phase has a lower conductivity by the order of at least two magnitudes. The results for our samples are in a good agreement with literature data. Tsai et al. reported a conductivity of $0.71 \cdot 10^{-3} \mathrm{~S} / \mathrm{cm}$ for LLZO with the same stoichiometry and sintered under similar conditions, which is close to our value of $0.65 \cdot 10^{-3} \mathrm{~S} / \mathrm{cm}$ [12]. Goodenough et al. found a conductivity of $0.3 \cdot 10^{-3} \mathrm{~S} /$ $\mathrm{cm}$ for tantalum substituted (Ta0.4) LLHO [28]. They did not include aluminium intentionally, but since they used alumina crucibles, it can be expected that aluminium was incorporated to some amount. The conductivity measured by Goodenough et al. is only slightly lower than the conductivity obtained in our work for a comparable composition, despite the different aluminium contaminations and sinter conditions.

Up to $10 \%$ of hafnium, the conductivity of LLZHO is relatively stable but strongly decreases for hafnium concentrations above $10 \%$. This behaviour can be explained when
Table.4 Fitted bulk and grain boundary resistances and capacitances of the CCD tested symmetrical cells. The impedance spectra were measured at $25^{\circ} \mathrm{C}$

\begin{tabular}{lllllll}
\hline & Hf0_1 & Hf0_2 & Hf016 & Hf08 & Hf16 & Hf_St \\
\hline$R_{\text {Bulk }}(\Omega)$ & 126.9 & 114.4 & 176.6 & 167.0 & 185.2 & 133.8 \\
$C_{\text {Bulk }}\left(10^{-11} \mathrm{~F}\right)$ & 3.61 & 5.74 & 9.22 & 9.36 & 8.59 & 8.95 \\
$R_{\mathrm{GB}}(\Omega)$ & 4.54 & 11.28 & 14.92 & 10.03 & 22.96 & 5.55 \\
$C_{\mathrm{GB}}\left(10^{-8} \mathrm{~F}\right)$ & 11.9 & 2.933 & 4.07 & 4.24 & 6.95 & 7.43 \\
\hline
\end{tabular}


Table.5 Selected Li-ion conductivities from literature and compared with own data

\begin{tabular}{lllll}
\hline Compound & Sintering conditions & $\begin{array}{l}\text { total conductiv- } \\
\text { ity }(\mathrm{S} / \mathrm{cm})\end{array}$ & $\begin{array}{l}\text { Activation } \\
\text { energy }(\mathrm{eV})\end{array}$ & Reference \\
\hline $\mathrm{Li}_{7} \mathrm{La}_{3} \mathrm{Zr}_{2} \mathrm{O}_{12}$ & $1130{ }^{\circ} \mathrm{C}, 12 \mathrm{~h}$ & $2 \cdot 10^{-6}$ & 0.49 & {$[39]$} \\
$\mathrm{Li}_{6.45} \mathrm{Al}_{0.05} \mathrm{La}_{3} \mathrm{Zr}_{1.6} \mathrm{Ta}_{0.4} \mathrm{O}_{12}$ & $1150{ }^{\circ} \mathrm{C}, 10 \mathrm{~h}$ & $0.71 \bullet 10^{-3}$ & 0.42 & {$[12]$} \\
$\mathrm{Li}_{6.45} \mathrm{Al}_{0.05} \mathrm{La}_{3} \mathrm{Zr}_{1.6} \mathrm{Ta}_{0.4} \mathrm{O}_{12}$ & $1175{ }^{\circ} \mathrm{C}, 10 \mathrm{~h}$ & $0.651 \bullet 10^{-6}$ & & This work \\
$\mathrm{Li}_{7} \mathrm{La}_{3} \mathrm{Hf}_{2} \mathrm{O}_{12}$ & $980^{\circ} \mathrm{C}, 5 \mathrm{~h}$ & $7 \cdot 10^{-7}$ & 0.53 & {$[40]$} \\
$\mathrm{Li}_{6.6} \mathrm{La}_{3} \mathrm{Hf}_{1.6} \mathrm{Ta}_{0.4} \mathrm{O}_{12}$ & $1130{ }^{\circ} \mathrm{C}, 48 \mathrm{~h}$ & $0.299 \bullet 10^{-3}$ & 0.440 & {$[28]$} \\
$\mathrm{Li}_{6.45} \mathrm{Al}_{0.05} \mathrm{La}_{3} \mathrm{Hf}_{1.6} \mathrm{Ta}_{0.4} \mathrm{O}_{12}$ & $1175^{\circ} \mathrm{C}, 10 \mathrm{~h}$ & $0.455 \bullet 10^{-3}$ & & This work \\
\hline
\end{tabular}

considering the conductivity mechanism in LLZO. The conductivity of a Li-ion conductor depends mainly on two different parameters: the concentration of mobile Li-ions and their mobility [22]. The optimal concentration of mobile $\mathrm{Li}^{+}$-ions was subject of many investigations and was found to have an optimal value between 6.4 and $6.5 \mathrm{~mol} \mathrm{Li}$ per unit cell $[28,29,36]$. By choosing a doping of Ta0.4 and Al0.05, we are perfectly within the optimum Li concentration. The mobility of the $\mathrm{Li}^{+}$ions is structurally influenced by the size of the Li migration channels. It is generally assumed that, by the incorporation of a larger ion in solid electrolytes, the $\mathrm{Li}^{+}$-ions have more space to move and therefore the conductivity rises [37]. This fits to our observation, where the incorporation of the smaller Hf-ions leads to a decrease in lattice parameter and conductivity.

Dendrite formation and growth is a complex phenomenon, and multiple parameters have to be observed. The impedance spectra of the symmetrical cells give information about the conductivity of the used LLZO. While the first two are used to calculate the total conductivity of the pellet and the fractions of bulk and grain boundaries resistance, the last resistance gives information about the contact between electrolyte and lithium. The next important information is the relative density of the pellet. From a pure mechanical point of view, one would expect the sample with the highest density to also have the highest resistance to dendrite formation, which is clearly not the case in our study. In general, samples with a higher conductivity show a higher CCD.

The Hf free sample Hf0_1 reached the highest CCD of $550 \mu \mathrm{A} / \mathrm{cm}^{2}$. The material failed, when the useable lithium depleted; the contact area shrank; and the cell polarised. The dendrite was formed when voltage reached 3.6 V. Due to strong polarisation and reduced contact area, the effective current density is probably higher and caused the material failure. With an improved contact or shorter stripping and plating times, a higher CCD should be measurable. The material had the highest conductivity of $0.73 \cdot 10^{-3} \mathrm{~S} / \mathrm{cm}$ and the lowest partial grain boundary resistance of $3.5 \%$ despite its mediocre density of $92.3 \%$. It is important to mention that other samples of the same batch (HfO_2) did not show the same performance. Some samples had a comparable density and a conductivity of around $0.7 \cdot 10^{-3} \mathrm{~S} /$ $\mathrm{cm}$, but a higher grain boundary resistance of $9 \%$. During their CCD tests, dendrites were formed already at current densities of $350 \mu \mathrm{A} / \mathrm{cm}^{2}$ without strong polarisation. This shows the strong influence of the grain boundary resistance and microstructure of the pellets and should be investigated in the future.

The second-best CCD of $450 \mu \mathrm{A} / \mathrm{cm}^{2}$ was achieved for the standard material LLZ_St. The dendrite was also formed after some polarisation at a voltage of $0.15 \mathrm{~V}$. The sample showed a good conductivity of $0.64 \cdot 10^{-3} \mathrm{~S} / \mathrm{cm}$ and a partial grain boundary resistance below $5 \%$. The CCD was reproducible in the range of $400-450 \mu \mathrm{A} / \mathrm{cm}^{2}$.

The third-best result with $425 \mu \mathrm{A} / \mathrm{cm}^{2}$ was observed for the $10 \%$ doped sample $\mathrm{HfO} 16$ and is in the same range as the reference material LLZ_St. Dendrite formation began at $0.017 \mathrm{~V}$, before a significant polarisation was observed. Therefore, the effective current density matches the applied current density. Despite its higher density, Hf016 has a higher proportion of grain boundary resistance and lower conductivity compared to Hf0 and Hf_St.

All other samples showed a worse performance, although some parameters were better. Especially, Hf08 shows in comparison to Hf016 that the partial grain boundary resistance is not the only governing factor for dendrite formation. The resistance is only $5.6 \%$ of the pellets resistance, but the conductivity is lower and results in a CCD of just $350 \mu \mathrm{A} /$ $\mathrm{cm}^{2}$. The pure Hf-phase Hf16 has the highest relative density of all materials, but the lowest conductivity and the highest partial grain boundary resistance. This results in the lowest CCD of $300 \mu \mathrm{A} / \mathrm{cm}^{2}$ and shows that a high density is clearly not a guarantee for a high CCD. In our opinion, the composition is a minor factor for the dendrite formation, and the reproducibility shows that a high conductivity paired with a low grain boundary resistance gives the best results.

\section{Conclusions}

The garnet structured ceramic Li-conducting electrolyte $\mathrm{Li}_{6.45} \mathrm{Al}_{0.05} \mathrm{La}_{3} \mathrm{Zr}_{1.6-x} \mathrm{Hf}_{x} \mathrm{Ta}_{0.4} \mathrm{O}_{12}$ was prepared with $x=0-1.6$ via a solid-state reaction. Up to $x=0.1$, the total Li-ion conductivity remained independent of the $\mathrm{Hf}$ 
content. Further increasing the hafnium concentration leads to a decrease in total conductivity, which is expected since a decrease of the lattice parameter is known to impede the Li-ion pathway. In terms of resistance to dendrite formation, symmetrical cell tests with $\mathrm{Li}$ metal electrodes show that the composition has only a minor influence on the CCD in comparison to the general effect of conductivity and grain boundary resistance stemming from the manufacturing and sintering process. Based on the obtained results, it can be concluded that the usage of cheaper $\mathrm{ZrO}_{2}$ precursors with higher percentage of hafnium impurities does not have a significant impact on the electrochemical performance of the material in ASBs. This result is encouraging, as the price for LLZO needs to drop significantly (below $50 \$ / \mathrm{kg}$ ) in order to be a viable option for large-scale industrial application [38].

Supplementary Information The online version contains supplementary material available at https://doi.org/10.1007/s11581-021-04300-w.

Acknowledgements The authors thank Dr. D. Sebold (IEK-1) for SEM investigations and the Central Institute of Analytics (ZEA-3) for the ICP-OES measurements.

Funding Open Access funding enabled and organized by Projekt DEAL. Furthermore, the financial support from the German Federal Ministry of Education and Research (BMBF) in the frame of the Festbatt project (FKZ: 13XP0173A), and the LISZUBA project (FKZ: 03XP0115B) is gratefully acknowledged.

\section{Declarations}

Conflict of interest The authors declare no competing interests.

Open Access This article is licensed under a Creative Commons Attribution 4.0 International License, which permits use, sharing, adaptation, distribution and reproduction in any medium or format, as long as you give appropriate credit to the original author(s) and the source, provide a link to the Creative Commons licence, and indicate if changes were made. The images or other third party material in this article are included in the article's Creative Commons licence, unless indicated otherwise in a credit line to the material. If material is not included in the article's Creative Commons licence and your intended use is not permitted by statutory regulation or exceeds the permitted use, you will need to obtain permission directly from the copyright holder. To view a copy of this licence, visit http://creativecommons.org/licenses/by/4.0/.

\section{References}

1. Randau S, Weber DA, Kötz O, Koerver R, Braun P, Weber A, Ivers-Tiffée E, Adermann T, Kulisch J, Zeier WG, Richter FH, Janek J (2020) Benchmarking the performance of all-solid-state lithium batteries. Nat Energy 5:259-270. https://doi.org/10.1038/ s41560-020-0565-1

2. Janek J, Zeier WG (2016) A solid future for battery development. Nat Energy 1:16141. https://doi.org/10.1038/nenergy.2016.141

3. Zhao Q, Stalin S, Zhao C-Z, Archer LA (2020) Designing solidstate electrolytes for safe, energy-dense batteries. Nat Rev Mater 5:229-252. https://doi.org/10.1038/s41578-019-0165-5
4. Thangadurai V, Narayanan S, Pinzaru D (2014) Garnet-type solidstate fast $\mathrm{Li}$ ion conductors for $\mathrm{Li}$ batteries: critical review. Chem Soc Rev 43:4714-4727. https://doi.org/10.1039/C4CS00020J

5. Samson AJ, Hofstetter K, Bag S, Thangadurai V (2019) A bird'seye view of $\mathrm{Li}$-stuffed garnet-type $\mathrm{Li}_{7} \mathrm{La}_{3} \mathrm{Zr}_{2} \mathrm{O}_{12}$ ceramic electrolytes for advanced all-solid-state Li batteries. Energy Environ Sci 12:2957-2975. https://doi.org/10.1039/C9EE01548E

6. Tsai C-L, Yu S, Tempel H, Kungl H, Eichel R-A (2020) Allceramic $\mathrm{Li}$ batteries based on garnet structured $\mathrm{Li}_{7} \mathrm{La}_{3} \mathrm{Zr}_{2} \mathrm{O}_{12}$. Mater Technol 35:656-674. https://doi.org/10.1080/10667857. 2020.1746539

7. Ramakumar S, Deviannapoorani C, Dhivya L, Shankar LS, Murugan R (2017) Lithium garnets: synthesis, structure, $\mathrm{Li}^{+}$conductivity, $\mathrm{Li}^{+}$dynamics and applications. Prog Mater Sci 88:325-411. https://doi.org/10.1016/j.pmatsci.2017.04.007

8. Zhao N, Khokhar W, Bi Z, Shi C, Guo X, Fan L-Z, Nan C-W (2019) Solid garnet batteries. Joule 3:1190-1199. https://doi. org/10.1016/j.joule.2019.03.019

9. Murugan R, Thangadurai V, Weppner W (2007) Fast lithium ion conduction in garnet-type $\mathrm{Li}_{7} \mathrm{La}_{3} \mathrm{Zr}_{2} \mathrm{O}_{12}$. Angew Chem Int Ed 46:7778-7781. https://doi.org/10.1002/anie.200701144

10. Zhu Y, He X, Mo Y (2015) Origin of outstanding stability in the lithium solid electrolyte materials: insights from thermodynamic analyses based on first-principles calculations. ACS Appl Mater Interfaces 7:23685-23693. https://doi.org/10.1021/ acsami.5b07517

11. Krauskopf T, Hartmann H, Zeier WG, Janek J (2019) Toward a fundamental understanding of the lithium metal anode in solid-state batteries - an electrochemo-mechanical study on the garnet-type solid electrolyte $\mathrm{Li}_{6.25} \mathrm{Al}_{0.25} \mathrm{La}_{3} \mathrm{Zr}_{2} \mathrm{O}_{12}$. ACS Appl Mater Interfaces 11:14463-14477. https://doi.org/10.1021/ acsami.9b02537

12. Tsai C-L, Roddatis V, Chandran CV, Ma Q, Uhlenbruck S, Bram M, Heitjans P, Guillon O (2016) $\mathrm{Li}_{7} \mathrm{La}_{3} \mathrm{Zr}_{2} \mathrm{O}_{12}$ interface modification for Li dendrite prevention. ACS Appl Mater Interfaces 8:10617-10626. https://doi.org/10.1021/acsami.6b00831

13. Li Y, Han J-T, Wang C-A, Xie H, Goodenough JB (2012) Optimizing $\mathrm{Li}^{+}$conductivity in a garnet framework. J Mater Chem 22:15357-15361. https://doi.org/10.1039/C2JM31413D

14. Tsai C-L, Dashjav E, Hammer E-M, Finsterbusch M, Tietz F, Uhlenbruck S, Buchkremer HP (2015) High conductivity of mixed phase Al-substituted $\mathrm{Li}_{7} \mathrm{La}_{3} \mathrm{Zr}_{2} \mathrm{O}_{12}$. J Electroceramics 35:25-32. https://doi.org/10.1007/s10832-015-9988-7

15. Lan W, Fan H, Lau VW-h, Zhang J, Zhang J, Zhao R, Chen $\mathrm{H}$ (2020) Realizing $\mathrm{Li}_{7} \mathrm{La}_{3} \mathrm{Zr}_{2} \mathrm{O}_{12}$ garnets with high $\mathrm{Li}^{+}$conductivity and dense microstructures by $\mathrm{Ga} / \mathrm{Nb}$ dual substitution for lithium solid-state battery applications. Sustain. Energy Fuels 4:1812. https://doi.org/10.1039/C9SE01162E

16. Ren Y, Liu T, Shen Y, Lin Y, Nan C-W (2016) Chemical compatibility between garnet-like solid state electrolyte $\mathrm{Li}_{6.75} \mathrm{La}_{3} \mathrm{Zr}_{1.75} \mathrm{Ta}_{0.25} \mathrm{O}_{12}$ and major commercial lithium battery cathode materials. J Materiomics 2:256-264. https://doi.org/10. 1016/j.jmat.2016.04.003

17. Park K, Yu B-C, Jung J-W, Li Y, Zhou W, Gao H, Son S, Goodenough JB (2016) Electrochemical nature of the cathode interface for a solid-state lithium-ion battery: interface between $\mathrm{LiCoO}_{2}$ and garnet- $\mathrm{Li}_{7} \mathrm{La}_{3} \mathrm{Zr}_{2} \mathrm{O}_{12}$. Chem Mater 28:8051-8059. https://doi.org/10.1021/acs.chemmater.6b03870

18. Uhlenbruck S, Dornseiffer J, Lobe S, Dellen C, Tsai C-L, Gotzen B, Sebold D, Finsterbusch M, Guillon O (2017) Cathode-electrolyte material interactions during manufacturing of inorganic solid-state lithium batteries. J Electroceramics 38:197-206. https://doi.org/10.1007/s10832-016-0062-x

19. Zhu Y, Connell JG, Tepavcevic S, Zapol P, Garcia-Mendez R, Taylor NJ, Sakamoto J, Ingram BJ, Curtiss LA, Freeland JW, Fong DD, Markovic NM (2019) Dopant-dependent stability 
of garnet solid electrolyte interfaces with lithium metal. Adv Energy Mater 9:1803440. https://doi.org/10.1002/aenm.20180 3440

20. Tsai C-L, Ma Q, Dellen C, Lobe S, Vondahlen F, Windmüller A, Grüner D, Zheng H, Uhlenbruck S, Finsterbusch M, Tietz F, Fattakhova-Rohlfing D, Buchkremer HP, Guillon O (2019) A garnet structure-based all-solid-state Li battery without interface modification: resolving incompatibility issues on positive electrodes. Sustain Energy Fuels 3:280-291. https://doi.org/10.1039/ c8se00436f

21. Finsterbusch M, Danner T, Tsai C-L, Uhlenbruck S, Latz A, Guillon O (2018) High capacity garnet-based all-solid-state lithium batteries: fabrication and 3D-microstructure resolved modeling. ACS Appl Mater Interfaces 10:22329-22339. https://doi.org/10. 1021/acsami.8b06705

22. Xiang X, Chen F, Yang W, Yang J, Ma X, Chen D, Su K, Shen Q, Zhang L (2020) Dual regulation of $\mathrm{Li}^{+}$migration of $\mathrm{Li}_{6.4} \mathrm{La}_{3} \mathrm{Zr}_{1.4} \mathrm{M}_{0.6} \mathrm{O}_{12}(\mathrm{M}=\mathrm{Sb}, \mathrm{Ta}, \mathrm{Nb})$ by bottleneck size and bond length of M-O. J Am Ceram Soc 103:2483-2490. https:// doi.org/10.1111/jace. 16920

23. Tong X, Thangadurai V, Wachsman ED (2015) Highly conductive Li garnets by a multielement doping strategy. Inorg Chem 54:3600-3607. https://doi.org/10.1021/acs.inorgchem.5b00184

24. Arnold B (2019) Zirkon, Zirkonium, Zirkonia - ähnliche Namen, verschiedene Materialien. Springer Spektrum, Berlin, Germany.

25. Xu L, Xiao Y, Sandwijk A, Xu Q, Yang Y (2014) Separation of zirconium and hafnium: a review. Energy Materials 2014, Conference Proceedings:451-457. https://doi.org/10.1002/9781119027 973.ch53

26. (September 2020). pp. Prices from: Alfa Aesar, Ward Hill, USA

27. Tietz F, Wegener T, Gerhards MT, Giarola M, Mariotto G (2013) Synthesis and Raman micro-spectroscopy investigation of $\mathrm{Li}_{7} \mathrm{La}_{3} \mathrm{Zr}_{2} \mathrm{O}_{12}$. Solid State Ion 230:77-82. https://doi.org/10. 1016/j.ssi.2012.10.021

28. Gupta A, Murugan R, Paranthaman MP, Bi Z, Bridges CA, Nakanishi M, Sokolov AP, Han KS, Hagaman EW, Xie H, Mullins CB, Goodenough JB (2012) Optimum lithium-ion conductivity in cubic $\mathrm{Li}_{7-\mathrm{x}} \mathrm{La}_{3} \mathrm{Hf}_{2-\mathrm{x}} \mathrm{Ta}_{\mathrm{x}} \mathrm{O}_{12}$. J Power Sources 209:184-188. https://doi.org/10.1016/j.jpowsour.2012.02.099

29. Thompson T, Sharafi A, Johannes MD, Huq A, Allen JL, Wolfenstine J, Sakamoto J (2015) A tale of two sites: on defining the carrier concentration in garnet-based ionic conductors for advanced Li batteries. Adv Energy Mater 5:1500096. https://doi.org/10. 1002/aenm.201500096

30. Liu K, Ma J-T, Wang C-A (2014) Excess lithium salt functions more than compensating for lithium loss when synthesizing $\mathrm{Li}_{6.5} \mathrm{La}_{3} \mathrm{Ta}_{0.5} \mathrm{Zr}_{1.5} \mathrm{O}_{12}$ in alumina crucible. $\mathrm{J}$ Power Sources 260:109-114. https://doi.org/10.1016/j.jpowsour.2014.02.065
31. Rodríguez-Carvajal J (1993) Recent advances in magnetic structure determination by neutron powder diffraction. Physica B Condens Matter 192:55-69. https://doi.org/10.1016/0921-4526(93) 90108-I

32. Logéat A, Köhler T, Eisele U, Stiaszny B, Harzer A, Tovar M, Senyshyn A, Ehrenberg H, Kozinsky B (2012) From order to disorder: the structure of lithium-conducting garnets $\mathrm{Li}_{7-\mathrm{x}} \mathrm{La}_{3} \mathrm{Ta}_{\mathrm{x}} \mathrm{Zr}_{2-\mathrm{x}} \mathrm{O}_{12}(\mathrm{x}=0-2)$. Solid State Ion 206:33-38. https://doi.org/10.1016/j.ssi.2011.10.023

33. Effenberger H, Zemann J (1979) Verfeinerung der Kristallstruktur des Lithiumkarbonates, $\mathrm{Li}_{2} \mathrm{CO}_{3}$. Z. Kristallogr. - Cryst. Mater 150:133-138. https://doi.org/10.1524/zkri.1979.150.14.133

34. Abbattista F, Vallino M, Mazza D (1987) Preparation and characterization of $\mathrm{La}_{2} \mathrm{Li}_{0.5} \mathrm{Al}_{0.5} \mathrm{O}_{4}$ with $\mathrm{K}_{2} \mathrm{NiF}_{4}$ structure. Inorg Chim Acta 140:147-149. https://doi.org/10.1016/S0020-1693(00) 81072-5

35. Shannon RD (1976) Revised effective ionic-radii and systematic studies of interatomic distances in halides and chalcogenides. Acta Cryst A 32:751-767. https://doi.org/10.1107/S05677394760015 51

36. Zhang Y, Chen F, Tu R, Shen Q, Zhang X, Zhang L (2016) Effect of lithium ion concentration on the microstructure evolution and its association with the ionic conductivity of cubic garnet-type nominal $\mathrm{Li}_{7} \mathrm{Al}_{0.25} \mathrm{La}_{3} \mathrm{Zr}_{2} \mathrm{O}_{12}$ solid electrolytes. Solid State Ion 284:53-60. https://doi.org/10.1016/j.ssi.2015.11.014

37. Bachman JC, Muy S, Grimaud A, Chang H-H, Pour N, Lux SF, Paschos O, Maglia F, Lupart S, Lamp P, Giordano L, Shao-Horn Y (2016) Inorganic solid-state electrolytes for lithium batteries: mechanisms and properties governing ion conduction. Chem Rev 116:140-162. https://doi.org/10.1021/acs.chemrev.5b00563

38. Albertus P, Babinec S, Litzelman S, Newman A (2018) Status and challenges in enabling the lithium metal electrode for high-energy and low-cost rechargeable batteries. Nat Energy 3:16-21. https:// doi.org/10.1038/s41560-017-0047-2

39. Buschmann H, Dölle J, Berendts S, Kuhn A, Bottke P, Wilkening M, Heitjans P, Senyshyn A, Ehrenberg H, Lotnyk A, Duppel V, Kienle L, Janek J (2011) Structure and dynamics of the fast lithium ion conductor " $\mathrm{Li}_{7} \mathrm{La}_{3} \mathrm{Zr}_{2} \mathrm{O}_{12}$." Phys Chem Chem Phys 13:19378-19392. https://doi.org/10.1039/C1CP22108F

40. Awaka J, Kijima N, Kataoka K, Hayakawa H, Ohshima K, Akimoto J (2010) Neutron powder diffraction study of tetragonal $\mathrm{Li}_{7} \mathrm{La}_{3} \mathrm{Hf}_{2} \mathrm{O}_{12}$ with the garnet-related type structure. J Solid State Chem 183:180-185. https://doi.org/10.1016/j.jssc.2009.10.030

Publisher's note Springer Nature remains neutral with regard to jurisdictional claims in published maps and institutional affiliations. 